\title{
Uma proposta prática de aprendizado para a disciplina de Geologia Urbana
}

\author{
Sueli Yoshinaga Pereira \\ Dept. de Geologia e Recursos Naturais, Instituto de Geociências, Univ. \\ Est. de Campinas - UNICAMP, Campinas, SP. \\ sueliyos@ige.unicamp.br \\ Pedro Wagner Gonçalves \\ Dept. de Geociências Aplicadas ao Ensino, Instituto de Geociências, Univ. \\ Est. de Campinas - UNICAMP, Campinas. \\ pedrog@ige.unicamp.br \\ Heraldo Cavalheiro Navajas Sampaio Campos \\ Centro de Apoio Operacional à Execução, CAEx. Ministério Público do \\ Estado de São Paulo, MPSP. \\ heraldocampos@mp.sp.gov.br
}

\begin{abstract}
A PROPOSAL OF PRACTICAL LEARNING FOR THE DISCIPLINE OF URBAN GEOLOGY. This article describes a learning proposal of an Urban Geology discipline, with emphasis on fieldwork, that has been applied in the Geology undergraduate course of the University of Campinas (UNICAMP). The discipline aims to develop among students a critical awareness of the performance and social function of a geologist. This perspective in behind the practical approach adopted throughout the term. Each programmatic subject is attended by a specific theoretical lesson, followed by a field visit and, eventually, a workshop. The three-yearexperience shows that most students understand the proposal and the importance of their attendance; however, there is a group of students that keep passive and develop a cartorial attitude towards learning. Eventually, although this innovation had been tested three times with only eighty students, the final results are considered positive. Citation: Pereira S.Y. , Gonçalves P.W. ,Sampaio H.C.C.N 2011. Uma proposta prática de aprendizado para a disciplina de Geologia Urbana. Terræ Didatica, 7(1):49$57<$ http://www.ige.unicamp.br/terraedidatica/>
\end{abstract}

\section{KEYWORDS Teaching of Geosciences, fieldwork, geological hazards, urban geology}

RESUMO Este trabalho apresenta uma proposta de aprendizado aplicada na disciplina de Geologia Urbana oferecida pelo curso de Geologia da Universidade Estadual de Campinas (UNICAMP) aos estudantes do $5^{\circ}$ ano, com ênfase para os trabalhos de campo. Pelo tipo de abordagem adotado ao longo do semestre, a disciplina visa despertar nos estudantes uma consciência crítica da futura profissão de geólogo e qual a sua função social. Para cada tema do programa foi montada uma aula teórica, seguida de visita de campo e finalizada com uma oficina. A experiência de três anos indica que parcela significativa dos alunos compreende a proposta e a importância de sua participação, mas há um grupo que permanece passivo e desenvolve atitude cartorial diante do ensino. Embora a inovação tenha sido testada somente três vezes, envolvendo pouco menos de 80 alunos, assinalamos que os resultados foram satisfatórios

PALAVRAS-CHAVE Ensino de Geociências, trabalhos de campo, riscos geológicos, Geologia Urbana

\section{Introdução}

O crescimento populacional desordenado das cidades brasileiras iniciado há algumas décadas devido a diversos fatores, como: várias crises econômicas, migração da população rural para áreas urbanas e falência de instituições públicas, levaram à edificação de cenários complexos de expansão urbana, em áreas inadequadas à ocupação. Os impactos e consequências de desastres naturais sobre essa realidade têm gerado, cada vez mais, conflitos e tragédias.

Os problemas decorrentes do uso e ocupação de terrenos situados em áreas de risco geológico poderiam ser evitados preventivamente por meio de planejamentos territoriais que utilizassem adequadamente a informação geológica. A ideia de um planejamento político e técnico está distante 
das tomadas de decisão; sua ausência implica a necessidade de se construir modelos para avaliar risco, bem como capacitar profissionais para usar tais modelos.

Os estudos brasileiros relativos a resolução e gerenciamento de áreas com problemas geológicos são extremamente objetivos e criativos, segundo métodos bem conhecidos e muito respeitados tanto pela comunidade local, como internacional. Servem de base para elaborar os modelos de avaliação de risco.

Atualmente, no curso de graduação em Geologia da Unicamp, existe a disciplina Geologia Urbana, que visa focar a aplicação dos conhecimentos geológicos adquiridos durante o curso, para identificar, caracterizar e resolver problemas geológicos decorrentes das atividades humanas em áreas urbanas principalmente das grandes metrópoles.

A disciplina mostra também que as soluções dos problemas possuem caráter interdisciplinar, ou seja, devem ser apresentados aos alunos não só os problemas geológico-geotécnicos e suas soluções técnicas, como também é preciso levá-los a refletir sobre as condições em que estes problemas foram gerados.

\section{Geologia e ambiente}

Das razões indicadas por Carneiro et al. (2004) para incluir temas geológicos na educação, seis são eminentemente ambientais. Segundo os autores, a Geologia contribui para:

- formar perspectiva humanística;

- entender o funcionamento do sistema Terra e do Tempo Geológico;

- avaliar risco geológico;

- conhecer os limites de recursos naturais;

- conhecer ideias de sustentabilidade;

- refletir criticamente sobre o ambiente.

Embora sejam motivos para incluir conhecimento geológico no ensino básico, advogamos que assinalam o lado aplicado e ambiental da Geologia que deve fazer parte da formação dos geólogos.

Essa interpretação não é despropositada, sobretudo quando consideramos as atividades comuns de geólogos de engenharia. A Association of Environmental \& Engineering Geologists (AEG), entidade sediada em Denver, Colorado, EUA, indica a atua- ção recente dos geólogos de engenharia. Mostra que a Geologia de Engenharia se desenvolveu a partir de problemas práticos da Engenharia e apoiou-se na especialização geológica para gerar e avaliar informações e recomendações para obras civis. Desse ponto de partida, avançou para interação com planejamento, trabalho em equipes multidisciplinares vinculadas aos operadores de políticas públicas e interesses de proprietários privados (ver AEG 2010). Dentre as atividades mais recentes dos geólogos de engenharia, os autores listam: avaliação de risco geológico a eventos, tais como: escorregamentos, falhas e terremotos, exposição radioativa do radônio e química do asbesto, subsidências, solos expansivos e colapsíveis etc. Destacamos esses campos de atuação profissional por serem atividades eminentemente urbanas. Geólogos de engenharia participam de outras atividades associadas ao meio urbano: avaliação de condições geológicas (incluindo estudos de aquíferos) que afetem o desenvolvimento residencial, comercial, industrial de uso de terrenos. Adicionalmente a AEG mostra o envolvimento com construções que necessitem tratar de estabilidade de encostas, abastecimento de água, esgoto, injeção de cimento e escavações. Além disso, geólogos de engenharia envolvem-se com a gestão, destinação de resíduos sólidos, bem como contribuem para estabelecer bases de remediação e mitigação de disposições ambientalmente inadequadas de resíduos sólidos (AEG 2010).

A definição de Geologia de Engenharia da Associação Brasileira de Geologia de Engenharia e Ambiental (ABGE) acompanha a definição da International Association for Engineering Geology and the Environment (IAEG), explora a ideia de que Geologia de Engenharia é área aplicada do conhecimento geológico, mas na apresentação das principais áreas de atuação, largamente coincide com as indicações da AEG (ABGE 2010).

É preciso reconhecer um descompasso entre a importância dos problemas de engenharia e ambientais que demandam conhecimento geológico e a adequada formação de profissionais.

Frodeman (2000) sugeriu que a própria ciência geológica precisa passar por mudanças em virtude da escassez do suporte da vida; isso implica repensar o próprio objeto de estudo para enfrentar os desafios postos pela atualidade.

Drummond e Markin (2008) levantam as disciplinas que compõem as grades curriculares de 278 cursos de Geologia dos EUA. Mostram 
que há um modelo de grade curricular comum à maioria dos cursos, na qual, mesmo disciplinas que consideramos importantes na comunidade brasileira, podem estar ausentes. Por exemplo, Estratigrafia acha-se presente em menos de dois terços dos cursos. Áreas aplicadas que ajudam a fazer aproximação problemas da engenharia e ambiente não são majoritárias. Hidrogeologia está presente em menos de um quinto dos cursos e Geologia Ambiental em pouco mais de $10 \%$. Geologia de Engenharia ou Geologia Urbana não aparecem nos cursos. Mesmo disciplinas básicas que contribuiriam para formação ambiental dos profissionais como Ciência do Sistema Terra (presente em 5\% dos cursos), não foram muito adotadas pelas escolas norte-americanas. Em larga escala, Drummond e Markin (2008) revelam que o currículo tradicional dos cursos de Geologia dos EUA concentra-se em Mineralogia e Petrologia, Sedimentologia e Geologia Histórica, Geologia Estrutural, Geologia de Campo.

Comparada a essa tradição curricular, a grade do curso de Geologia da Unicamp mostra-se inovadora: Geologia Urbana e Geotecnia tratam da Geologia de Engenharia e incluem abordagem ambiental; o curso oferece ainda a disciplina Mecânica de Solos e Rochas, para formar um suporte geotécnico que contribui para capacitar os estudantes a mobilizar o conhecimento geológico e a interagir com atividades de Engenharia.

A tentativa de ajudar o aluno a formar uma ideia do ambiente, em escala local, regional e global, é reivindicada por Lutz e Srogi (2010). Os autores argumentam que em muitos cursos os estudantes aprendem procedimentos científicos das Geociências. Perguntam: por que os cursos só tratam de métodos e resultados de pesquisas? Não se deve ir além disso para desenvolver habilidades para cidadania e gestão? Argumentam que os alunos precisam compreender como as pessoas percebem, interagem e avaliam o mundo natural. Isso implica formação de valores que transcendam os problemas pertencentes estritamente à ciência. Exemplificam com seu próprio trabalho em que conteúdos científicos vinculam situações e problemas desafiadores para a sociedade norte-americana. Essas situações conduzem a considerar a natureza e suas inter-relações com atividades sociais, econômicas e culturais.

Aproximar os alunos diretamente de situações e problemas ambientais motivou a reorganização da disciplina Geologia Urbana. A perspectiva foi pôr o estudante em contato direto com atividades comuns da vida profissional.

Para entender os problemas ambientais por meio da perspectiva geológica foi preciso examinar como Geologia Urbana tomava parte da formação profissional dos alunos da Unicamp. Em primeira aproximação, foi necessário refletir, avaliar e construir um esquema para formação do geólogo. Isso conduziu a identificar três momentos relativos ao conhecimento geológico, ou seja, três âmbitos diferentes da formação profissional: (a) domínio sobre funcionamento e efeitos de processos e eventos geológicos, (b) domínio de modelos de risco e, logo em seguida, (c) domínio sobre avaliação final do risco.

O primeiro momento corresponde à etapa anterior ao ingresso dos alunos na disciplina. Os alunos do quinto ano de Geologia já fizeram quase toda instrução geológica básica. Isso cobre processos terrestres e seu funcionamento sistêmico no tempo geológico, Mineralogia e Petrologia, Geologia Estrutural, Estratigrafia. Durante todo o curso, alunos estudaram processos e produtos geológicos. Isso possibilita que os alunos possam examinar situações-problema e fazerem previsões sobre o futuro desenvolvimento de processos, tais como enchentes, erosão acelerada, escorregamentos etc. Trata-se de pressuposto assumido pela disciplina: estudantes já dominam o conhecimento geológico, necessitam mobilizar tais conhecimentos para fazer previsões de situações locais específicas - o quadro já esboçado de problemas urbanos. É importante assinalar, portanto, que a disciplina supõe que os estudantes possam explicar processos e eventos relativos a vulcanismo, sismicidade, clima em escala regional e local, bem como considerar a escala planetária.

O segundo momento é interno à disciplina. É necessário enfatizar e explorar modelos que possibilitem aos alunos avaliar o risco natural vinculado a cada processo geológico. Isso implica examinar interações de fenômenos com atividades sociais para poder avaliar o risco.

O terceiro momento acompanha e avança o anterior. É preciso levar em conta várias dimensões para alcançar a avaliação final do risco. Implica um esforço interdisciplinar que considera aspectos técnicos, econômicos e culturais dos grupos humanos envolvidos e afetados pelos eventos geológicos que produzem perdas à sociedade. 
A identificação desses momentos implicou estabelecer certas diretrizes para orientar o programa de Geologia Urbana:

- apresentar os problemas urbanos relacionados à Geologia;

- ensinar e vivenciar os problemas geológicos na prática;

- apresentar os mais diversos procedimentos para gerenciar e ou mitigar problemas de caráter geológico;

- contatar profissionais de instituições renomadas, com grande experiência nas áreas abordadas, e convidá-los a oferecer palestras.

\section{Objetivos deste trabalho}

O objetivo mais amplo deste trabalho é enfatizar a importância de trabalhos práticos, situaçõesproblema, desafios urbanos e ambientais, questões locais para formação dos geólogos.

O texto discute, ainda, a relevância da Geologia de Engenharia e mais especificamente da Geologia Urbana para formação profissional. Pretendese, finalmente, descrever atividades realizadas na disciplina Geologia Urbana da Unicamp, que foi ministrada nos anos de 2008 a 2010 aos alunos de Geologia.

\section{Ementa, objetivo e programas da disciplina}

A disciplina apresenta uma carga horária de 60 horas e apresenta a seguinte ementa e objetivos:

EMENTA: Gestão, supervisão, orientação técnica sobre Geologia Ambiental. Coleta de dados, planejamento e projeto geológicos do uso e ocupação do solo urbano. Estudo e recuperação ambiental de solos e águas subterrâneas contaminadas, implantação de aterros de resíduos sólidos e avaliação de impactos ambientais, risco geológico (erosão, inundações, instabilidade de encostas). Cartas geotécnicas, planejamento do uso racional de recursos minerais e hídricos. Visita técnica a casos de tratamento de resíduos, levantamento de contaminação e risco geológico.

OBJETIVO: O curso visa capacitar o aluno a: (1) identificar os impactos da atividade humana no meio físico e as alternativas de suas soluções, (2) caracterizar e aplicar os conhecimentos e metodologias que vêm sendo desenvolvidos em geologia para subsidiar ações de gestão urbana e ambiental, (3) supervisionar e coordenar aspectos relativos a importância da visão holística para os estudos multi e inter-disciplinares em projetos de planejamento territorial e de mitigação de impactos ambientais existentes, (4) planejar a proteção, preservação e solução de problemas urbanos e ambientais sob a ótica do desenvolvimento sustentável.

Os programas e as atividades desenvolvidas para a disciplina de Geologia Urbana nos anos de 2008 e 2009 estão descritos a seguir.

\subsection{Programa 2008}

A disciplina está estruturada em aulas, trabalhos de campo, oficinas e palestras. No ano 2008 as atividades realizadas foram basicamente:

- apresentação do curso; estruturação das equipes e apresentação do método de avaliação; atividade - carta de reclamação ao prefeito;

- trabalho de campo; cadastro de poços no Campus com base na Portaria DAEE n 717 ;

- oficina sobre o cadastramento de poços;

- trabalho de campo; enchentes em Barão Geraldo;

- oficina sobre as enchentes em Barão Geraldo;

- palestra sobre risco geológico;

- trabalho de campo; áreas de risco geológico em Souzas;

- oficina sobre as áreas de risco geológico em Souzas;

- palestra sobre mineração em áreas urbanas;

- trabalho de campo; cadastro de voçoroca em Campinas;

- oficina sobre o cadastro de voçoroca e de aterro/ lixão em Campinas;

- palestra sobre erosão e assoreamento;

- trabalho de campo; Rodovia Anchieta na Serra do Mar e problemas de fundação na cidade de Santos;

- oficina sobre a cidade de Santos - prédios inclinados próximos à orla marítima.

O programa de 2008 introduziu profunda inovação curricular no desenvolvimento da disciplina. 
A partir da ideia-chave de valorização de situaçõesproblema locais para desafiar os estudantes e ajudálos a mobilizar seu conhecimento geológico para identificar, diagnosticar e avaliar riscos geológicos envolvidos e, na medida do possível, aplicar um modelo de risco para sugerir recomendações ao setor público ou privado.

Isso implicou estruturar a dinâmica apoiada no campo e em oficinas de discussão do campo. As aulas de campo consistiram de detectar as causas da existência de situação problema envolvendo certo risco geológico. Por meio das observações sobre as rochas e suas estruturas, seu estado de alteração, solos existentes e presença de colúvios, disposição do relevo, redes de drenagem, nascentes, e o uso e ocupação do terreno. As oficinas dedicaram-se a análises feitas pelos estudantes, embasadas pela pesquisa bibliográfica feita durante a semana após o trabalho de campo; as soluções sobre como resolver problemas detectados eram então avaliadas e sugeridas.

O campo abrangeu os seguintes assuntos: cadastramento de poços tubulares profundos do campus da Unicamp, com o preenchimento dos formulários oficiais da Portaria 717 do Departamento de Águas e Energia Elétrica (DAEE) e discussão sobre hidrogeologia em áreas urbanas; visita às áreas de inundação no Distrito de Barão Geraldo, com apresentação das causas de inundação, os problemas detectados e os conflitos entre uso do solo urbano e áreas inundáveis. Os problemas de risco geológico, no caso escorregamento e rolamento de blocos foram apresentados em forma de palestra de profissionais convidados, que atuam no gerenciamento dessas áreas no estado de São Paulo. Dr. Jair Santoro do Instituto Geológico, Secretaria Estadual do Meio Ambiente do Estado de São Paulo, foi convidado para explanar sobre o assunto e explicar o sistema implantado na Defesa Civil há aproximadamente 20 anos pelo governo do Estado de São Paulo, que monitora durante os meses mais chuvosos as áreas de risco da Serra do Mar; hoje, o programa se estende a outras cidades do Estado de São Paulo.

Houve trabalho de campo sobre escorregamento estudado em visita na região de Souzas, leste de Campinas, área de ocorrência de rochas do embasamento e intrusão granítica, de grandes estruturas geológicas (falhas e zonas de cisalhamento), e, portanto de maiores declividades, cujo manto de alteração é extremamente erodível. A implantação de loteamentos de alto padrão, as construções de residências em áreas muito declivosas foram os objetos de aula e oficina.

A mineração de agregados em áreas urbanas foi assunto que mereceu atenção especial da disciplina. O Dr. Omar Yazbek Bitar, do Instituto de Pesquisas Tecnológicas (IPT), foi convidado para discutir o problema com os alunos. Tratou da situação dos agregados para a construção civil e seus problemas com a urbanização, bem como áreas recuperadas foram apresentadas (por exemplo, o Parque do Ibirapuera da cidade de São Paulo).

Para iniciar o desenvolvimento do tema erosão e assoreamento durante o transcorrer da disciplina no curso, a palestra do MSc. Gerson Salviano de Almeida Filho do Instituto de Pesquisas Tecnológicas (IPT) abordou o assunto apresentando as suas principais causas e consequências para diversas áreas do meio rural e urbano no Estado de São Paulo.

Áreas de boçorocas recuperadas foi outro tema selecionado. Há em Campinas, na região da bacia hidrográfica do Capivari (oeste do município), uma área com alta suscetibilidade a erosão e boçorocamento. Muitas áreas com boçoroca foram recuperadas na região. $\mathrm{O}$ trabalho de campo consistiu em conhecer áreas recuperadas ou em recuperação na época, caracterizar o material erodível, uso e ocupação da terra no local (região de periferia de Campinas) e os vários tipos de recuperação de boçoroca. Assim apresentou-se aos alunos o Parque Carlos Marighela, em fase de construção final na época da visita. Alunos conheceram também boçoroca recuperada e transformada no Parque dos Cambarás.

Por fim, uma última visita foi realizada conjuntamente com a disciplina Geotecnia, que consistiu de viagem a Santos, passando pela rodovia Anchieta. $\mathrm{Na}$ viagem foram apresentados a história da construção da rodovia e seus problemas geotécnicos, exemplificados pelo abandono de um viaduto construído sobre área instável de acumulação de tálus, como resultado da falta de avaliação geológica no projeto e nas obras. $\mathrm{Na}$ viagem de estudo foram destacados problemas de movimento de massa, como escorregamentos, muito comuns nesse cenário geológico. Além disso, alunos reconheceram exemplos da orla costeira da cidade de Santos, onde há problemas de fundações em solos colapsíveis, monitoramento de prédios construídos sem critérios geológicos e obras de recuperação de 
prédios com problemas nas fundações.

\subsection{Programa 2009-2010}

A partir das sugestões dos alunos, feitas no ano de 2008, foram introduzidas mudanças que buscaram aperfeiçoar os procedimentos didáticos.

O programa foi estruturado de forma a que cada tema fosse organizado com uma aula teórica, seguido da visita ao campo e discussão em oficina. Nas aulas teóricas teriam também quando possível uma palestra com um convidado especialista no tema. Dessa maneira, a parte teórica passou a explicitamente apresentar um modelo de análise para situação de risco que seria descrita no campo e discutida na oficina, foi um modo de explorar processos específicos e seus efeitos ambientais.

Desta maneira o Programa dos anos 2009-2010 foi assim estruturado:

- apresentação do curso; estruturação das equipes e apresentação do método de avaliação; atividade - carta de reclamação ao prefeito;

- levantamento hidrogeológico básico;

- trabalho de campo; cadastro de poços no Campus com base na Portaria DAEE n ${ }^{\circ} 717$;

- oficina sobre o cadastramento de poços;

- riscos geológicos - enchentes;

- trabalho de campo; enchentes em Barão Geraldo;

- oficina sobre as enchentes em Barão Geraldo;

- palestra sobre risco geológico - escorregamentos e defesa civil;

- trabalho de campo; áreas de risco geológico em Souzas;

- oficina sobre as áreas de risco geológico em Souzas;

- palestra sobre erosão e assoreamento;

- visita a área de voçoroca remediada em Campinas (DIC) - situação atual;

- trabalho de campo. Visita aos bairros cota na Serra do Mar e na cidade de Santos. Cadastro de áreas críticas;

- oficina sobre a visita técnica ao IPT, visita aos bairros cota na Serra do Mar e na cidade de Santos;
- visita à Companhia Paulista de Força e Luz (CPFL), em Americana.

Assim o programa de 2009 foi montado com aulas sobre Hidrogeologia em áreas urbanas e estudos de levantamento hidrogeológico básico. Poucas modificações foram feitas para a edição 2010 da disciplina. A visita a poços tubulares da Unicamp e preenchimento de formulários para cadastramento de poços tubulares foram a tônica desta aula. A oficina apresenta então o trabalho realizado pelos alunos e apresentação dos resultados deste levantamento, utilizando informações adicionais como imagens de satélite, localização em GPS e perfis de poços cedidos pela Prefeitura do campus.

A visualização dos problemas encontrados no campo dispondo-os em mapas ou imagens de satélites disponíveis na Internet foram os instrumentos utilizados pelos alunos para o entendimento dos problemas apontados em campo. A noção de escala, o contexto mais regional deste problema foi espontaneamente identificado pelos alunos na oficina.

O risco geológico associado a movimentos de massa (escorregamentos e corridas) neste ano foi também apresentado pelo especialista Dr. Jair Santoro, do Instituto Geológico, que apresentou sua vivência e os trabalhos executados pelos geólogos de sua instituição e do IPT. O caso da catástrofe ocorrida em novembro de 2008 em Santa Catarina e o trabalho da Defesa Civil de São Paulo naquele estado foi apresentado e discutido. Ênfase foi dada aos procedimentos utilizados para levantar informações em meio às dificuldades de locomoção no ambiente onde houve enchentes, corridas de lama e escorregamentos na região de Itajaí, Palhoça e Blumenau.

Ainda neste ano visitaram-se os mesmos locais de ocorrência de boçorocas, e verificou-se que, na visita da Praça Carlos Marighela do ano anterior, obras de engenharia estavam sendo executadas para recuperar área de boçorocamento. No ano de 2009 esta obra estava pronta, podendo-se então fazer considerações sobre as obras realizadas e o que estava pronto no ano seguinte.

Por fim destaca-se a visita de campo junto com a Defesa Civil de Cubatão, ocasião em que os técnicos apresentaram os programas existentes no município para as áreas de risco. Ainda houve a visita à área do bairro do Grotão, situado próximo à rodovia Anchieta e dentro de área de preservação permanente. A rede de esgoto e de água instalada pela própria comunidade local foi apresentada aos 
alunos, que caminharam nas vias construídas. $\mathrm{O}$ problema de lixo e despejos de esgoto na drenagem foram alguns dos temas discutidos na área. Os alunos puderam então vivenciar os problemas existentes nestas áreas de risco a escorregamento e enchente, com uma ocupação densa de população de baixa renda. Diversos indícios de movimento de massa (rachaduras e áreas já escorregadas) foram observados. Visitou-se, ainda, na cidade de Santos, o bairro Regência, onde já foi área de risco e hoje está completamente urbanizada. As duas áreas são exemplos de estágios de processos de ocupação em áreas de risco e dos programas que estão em desenvolvimento e implantados já há algum tempo nos quais os profissionais formados na Unicamp podem vir a trabalhar.

Por fim a última visita de campo foi à Companhia de Força de Luz (CPFL), em Americana, onde foi apresentada a participação do geólogo nos processos de desinstalação de antigas indústrias e manutenção de reservatórios.

O campo propiciou condições para conhecer projeto de identificação de áreas contaminadas por usina termoelétrica desativada e medidas de remediação para que o terreno seja devolvido ao poder público.

As fotos de numeração de 1 a 6 apresentam alguns dos locais visitados e os assuntos discutidos em aula.

\section{Discussão: limitações da inovação}

A inovação curricular implementada no âmbito da disciplina Geologia Urbana propicia aos alunos um contato mais realista e prático com atividades profissionais que podem desempenhar no mercado de trabalho. Depoimentos dos alunos revelam que mesmo quando tinham conhecimento prévio de problemas ambientais e riscos geológicos associados não saberiam como atuar para mitigar ou solucionar situações de erosão acelerada ou escorregamentos. Isso sugere que é essencial discutir modelos de risco e criar condições favoráveis para que os próprios alunos apliquem esses modelos na elaboração de diagnósticos e indicação de recomendações para minimizar o risco envolvido em situações-problema ou casos.

A elaboração do diagnóstico que envolve tanto o conhecimento geológico básico, quanto o modelo para análise do risco - ideia de aplicação da Geologia que é a definição aceita de Geologia de Engenharia - depende da capacidade dos alunos de mobilizar conceitos, explicações de processos para utilizar modelos de risco geológico. Neste momento, notamos que algumas vezes os alunos possuem pouca familiaridade com habilidades práticas, tais como: elaborar croqui de um local, extrair informação relevante a partir de uma fotografia etc. Assinalamos, ademais, que tais habilidades são relevantes para inúmeras situações profissionais.

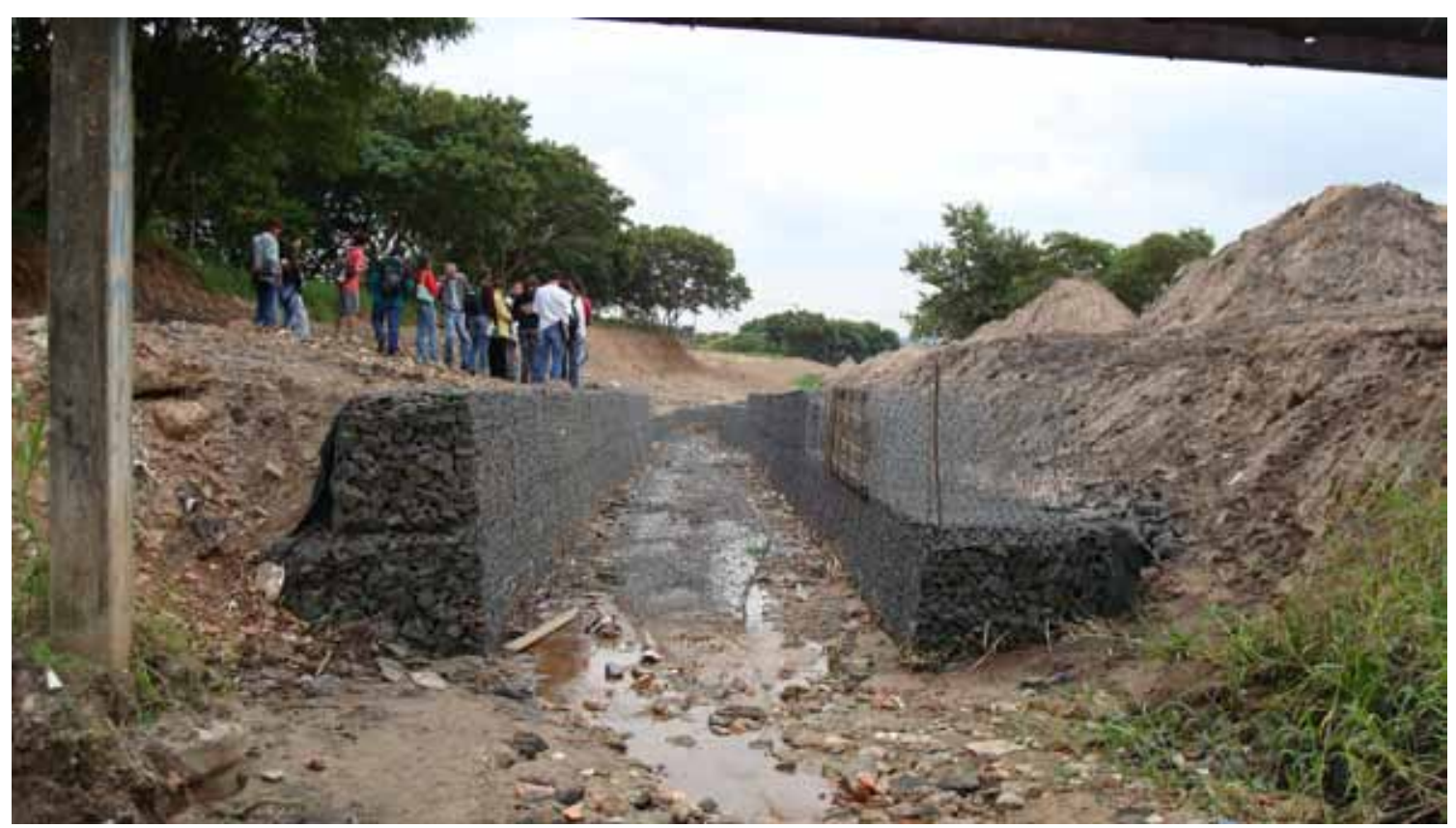

Foto 1. Visita à Praça Carlos Marighela, Campinas, projeto de contenção de boçoroca (2008). Foto: Heraldo Campos 


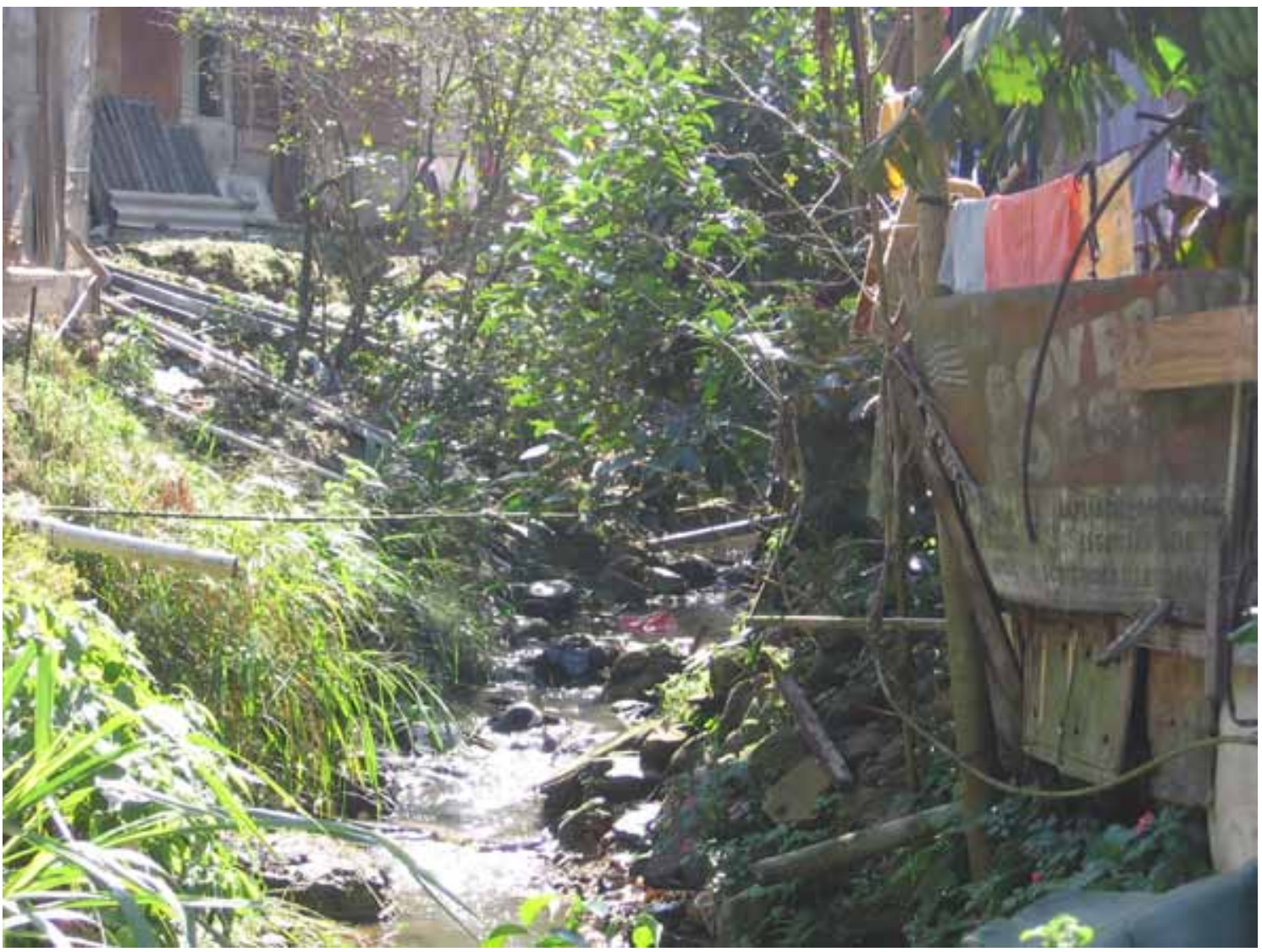

Foto 2. Bairro do Grotão, Cubatão, despejo de esgotos in natura no córrego em área de risco (2009). Foto: Pedro W. Gonçalves

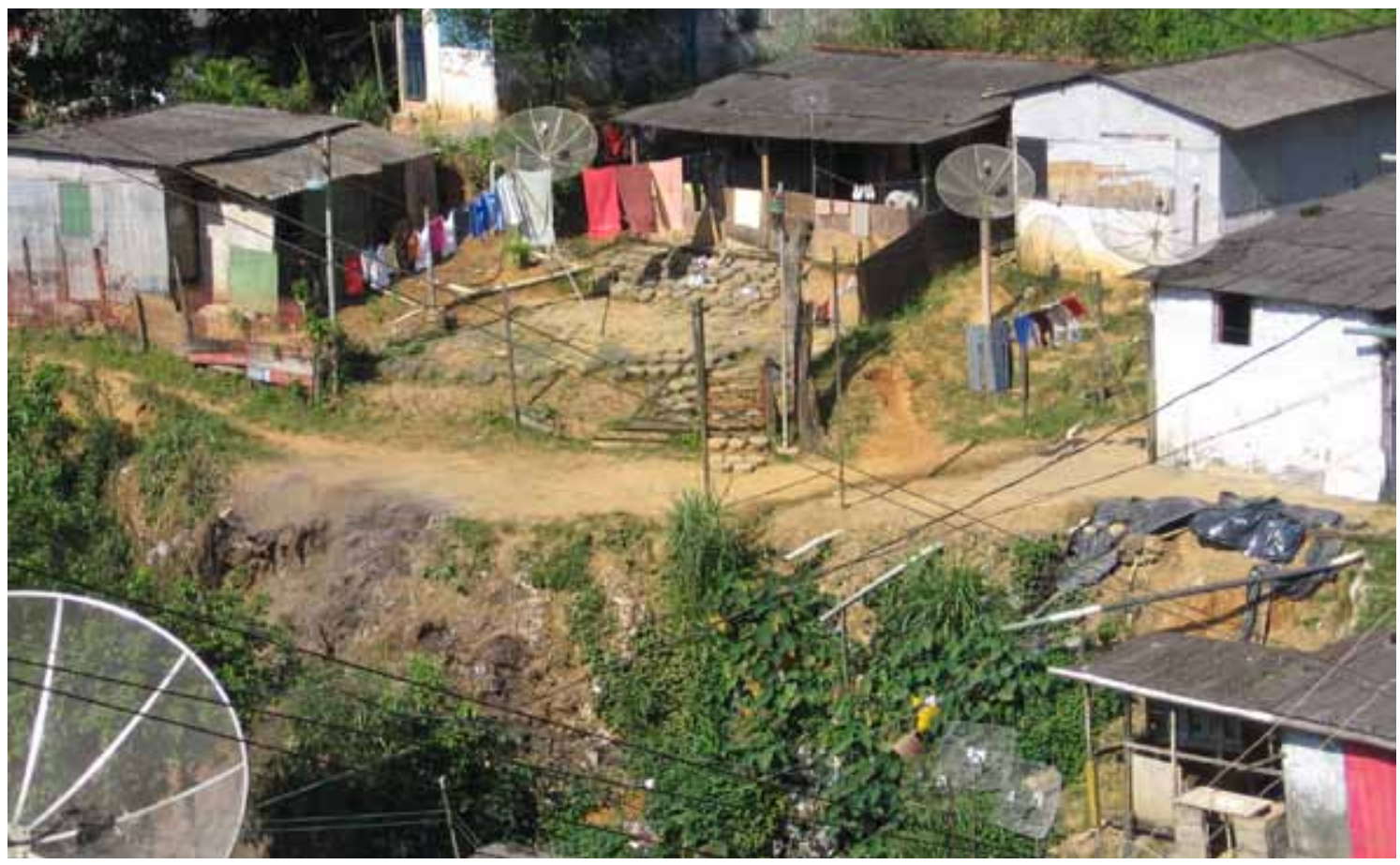

Foto 3. Bairro do Grotão, Cubatão, área de alto risco (2009). Foto: Pedro Wagner Gonçalves 


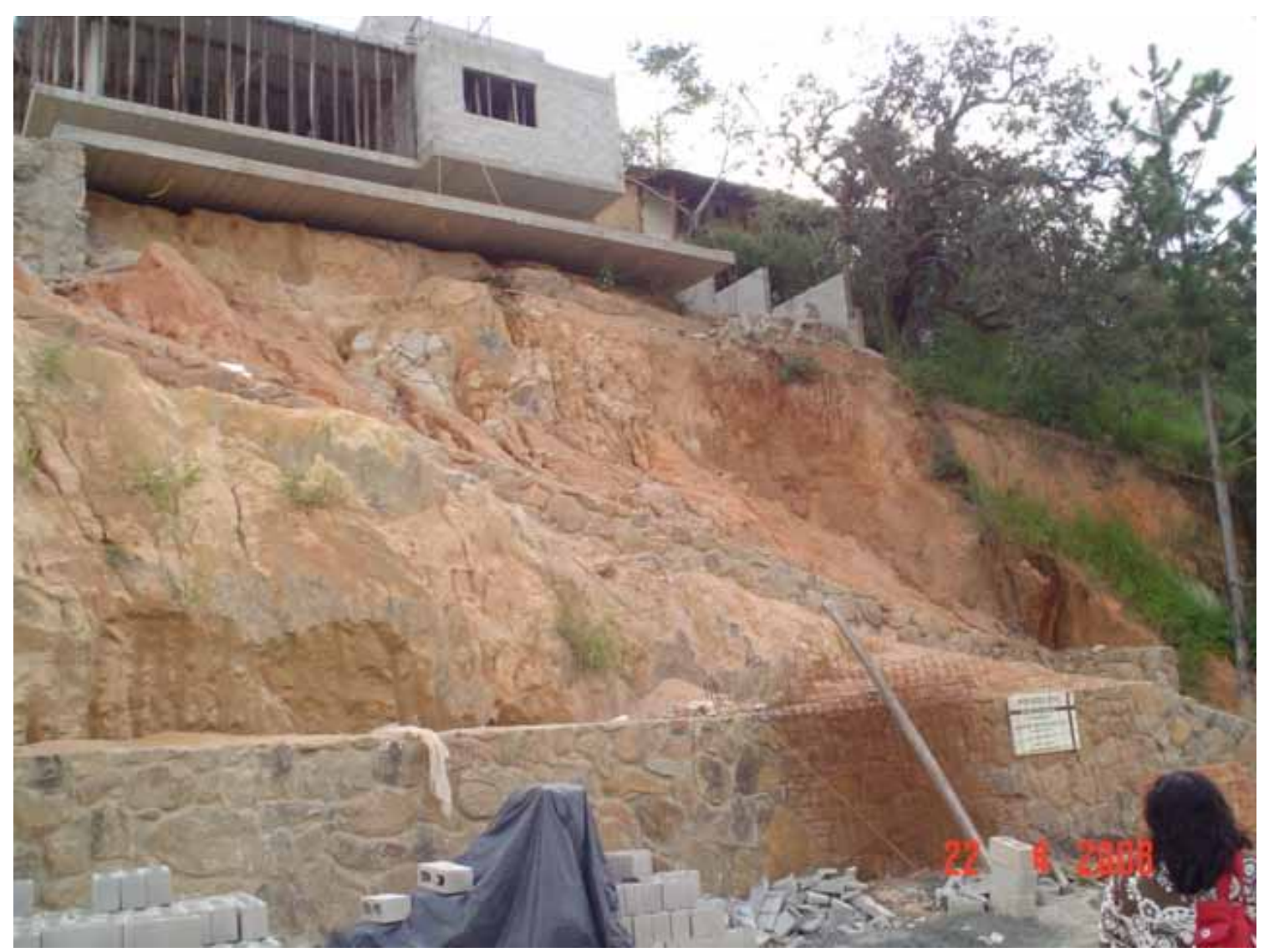

Foto 4. Bairro de Souzas, Campinas, loteamentos em área de alta declividade (2009). Foto: Pedro Wagner Gonçalves

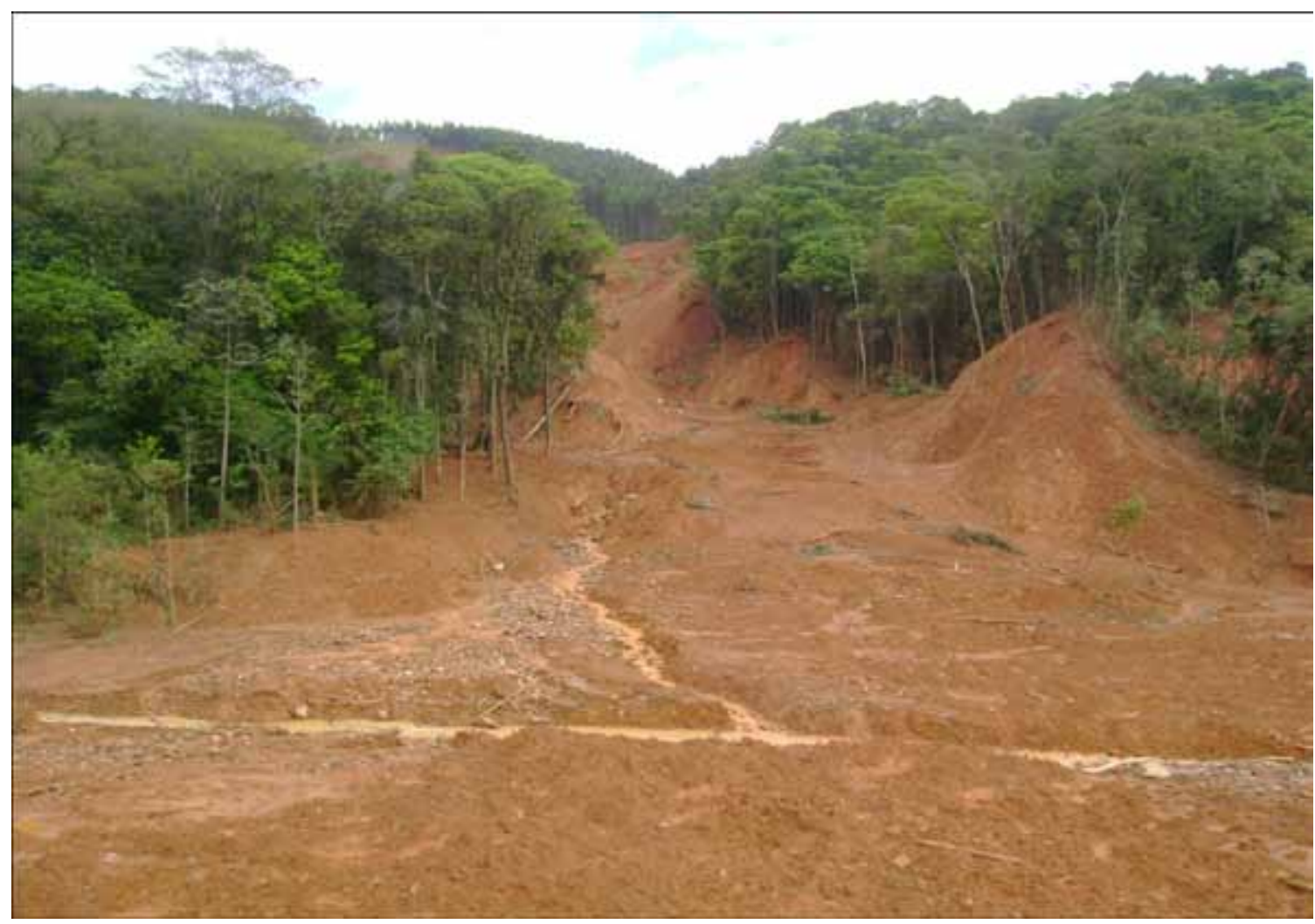

Foto 5. Local de escorregamento em Santa Catarina; palestra de Gerson Salviano de Almeida Filho. Foto: IPT 2008 


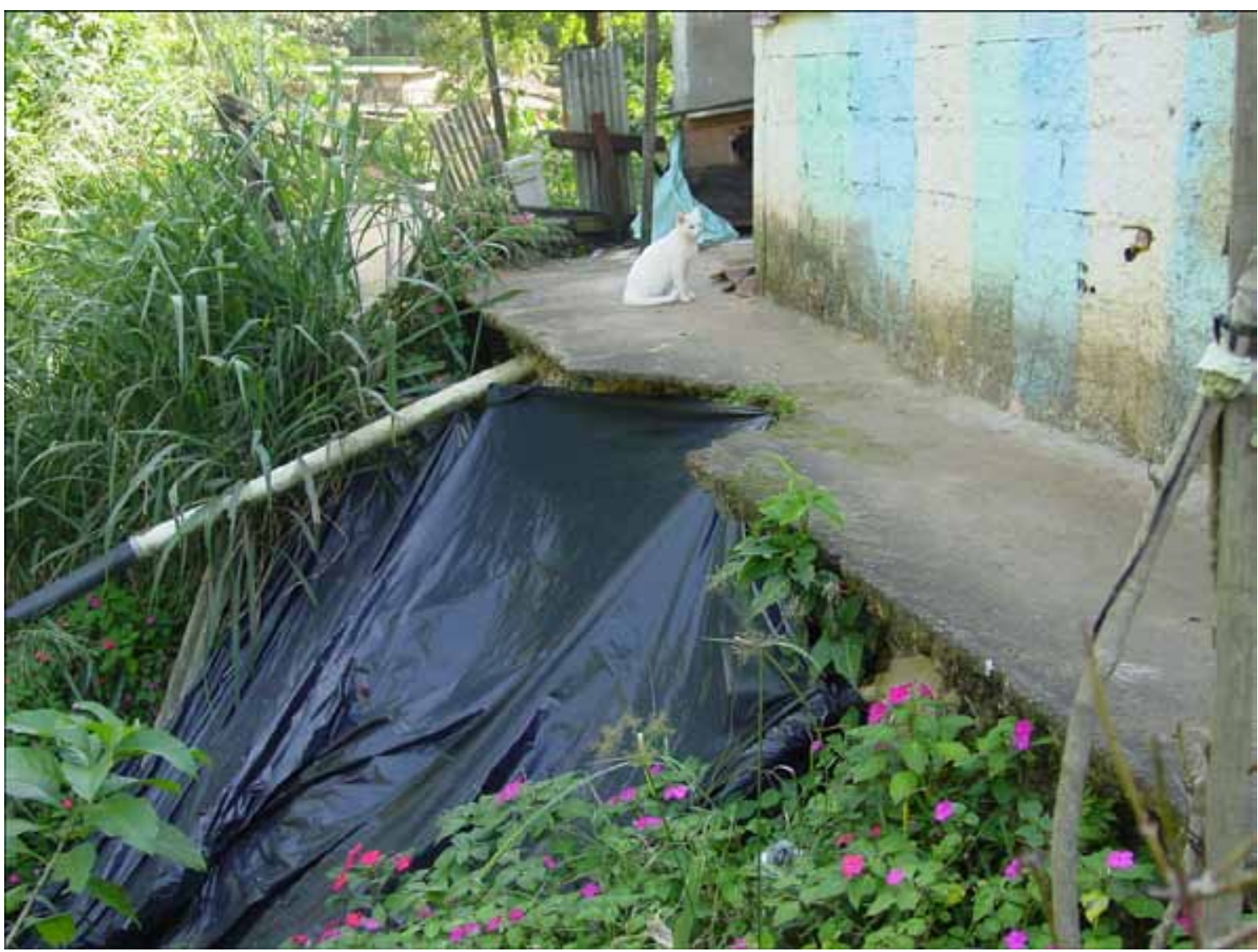

Foto 6. Área com escorregamento sob residência; cobertura de lona para evitar infiltração de água, Bairro do Grotão, Cubatão. Foto: Rogério Marcon

Os diagnósticos de situações de risco dependem, ainda, de conhecimento da geologia regional e local. Boa parte das situações de risco exploradas pela disciplina situa-se na região de Campinas ou limita-se ao Estado de São Paulo. Alguns alunos não conhecem a geologia da Bacia do Paraná ou as características geológicas e estruturais dos Grupos São Roque e Açungui. Esse limitado conhecimento da geologia cria obstáculos para aprendizagem de como aplicar os modelos de risco tratados pela disciplina. Ao mesmo tempo, o caráter fortemente prático que a disciplina adquiriu oferece poucas oportunidades de revisão da falta de conteúdo geológico dos alunos.

A articulação de atividade de campo e oficina desloca o processo de ensino para iniciativa do aluno e tira o professor do centro das atividades educacionais, sobretudo no momento de preparação das oficinas. Isso implica que o engajamento do aluno no seu próprio processo de aprendizagem é etapa essencial do seu aproveitamento. Dessa maneira, a disciplina depende do valor que os alunos atribuem à Geologia Urbana ou, mais amplamente à Geo- logia de Engenharia e Ambiental para sua própria formação. A experiência desses dois anos indica que parcela significativa dos alunos compreende a proposta e a importância de sua participação, mas há um grupo que permanece passivo e desenvolve uma atitude cartorial diante do ensino (alunos que simplesmente procuram obter os créditos necessários para completar o curso). Alguns alunos alegam que não pretendem trabalhar com Geologia de Engenharia ou Geologia Ambiental - o que não pode ser previsto por qualquer aluno.

Finalmente, é preciso assinalar que a inovação foi testada somente três vezes e envolveu pouco menos de 80 alunos. Foge dos limites deste trabalho tentar generalizar e prescrever tanto o conteúdo, quanto o modo como foi desenvolvido para todas as disciplinas de Geologia de Engenharia destinadas a formar geólogos. Em virtude disso, assinalamos que os resultados foram satisfatórios considerando os problemas e dificuldades do curso acima referidos.

A análise das avaliações dos alunos dos cursos de 2007 (antiga proposta), 2008 (implantação da nova proposta) e 2009 (proposta atual, reaplicada 
em 2010) indica que houve no geral uma intensificação da participação dos alunos nas atividades e discussões, aumento de consultas extra-classe aos professores, melhoria do desempenho do aluno e aumento da estimulação dos professores à participação dos alunos em aulas. Os alunos avaliam todas as disciplinas da Universidade por meio de questionário aplicado e organizado pela Coordenação de Graduação. Os pontos positivos apontados nessa avaliação foram justamente os trabalhos de campo e aulas práticas e palestras com profissionais atuantes nos temas abordados.

Em 2008, com a implantação da nova proposta houve estranhamento por alguns alunos pela ausência de aulas teóricas e de alguns problemas decorrentes dos trabalhos de campo (planejamento), com sugestões para haver aulas preparatórias, que seriam a base teórica, para os trabalhos de campo. Em 2009, após as modificações sugeridas e discutidas quer em classe quer nas avaliações, nota-se a mesma avaliação em termos de estímulo, aprendizado e práticas, cujos pontos positivos foram as atividades de campo, oficinas, palestras e sistema de avaliação. $\mathrm{O}$ aspecto negativo, na opinião dos alunos, hoje se encontra na formatação de um roteiro para as oficinas de modo que a apresentação e discussão com as equipes de alunos não sejam repetitivas.

\section{Considerações finais e conclusões}

Os alunos participantes, auxiliados pelos professores, reconheceram a importância de que, em quaisquer diagnósticos de situações de risco depende-se, intensamente, de bons conhecimentos da geologia regional e local. O maior conhecimento sobre a geologia local pode ser adquirido em outras disciplinas mais básicas, como também em iniciações científicas, que promovam a inserção de viagens de campo em regiões próximas, que sejam típicas das principais formações geológicas do estado de São Paulo.

Este trabalho apresentou uma proposta de aprendizado que enfatizou os trabalhos de campo e possibilitou formar nos alunos uma visão multi e interdisciplinar dos principais problemas geológicos existentes no âmbito e no campo de abordagem da disciplina de Geologia Urbana. Esta forma de abordagem tem mostrado que as atividades práticas desenvolvidas ao longo de um semestre letivo podem despertar mentes e corações na busca de um caminho de trabalho mais voltado para a compreensão e atuação junto das comunidades envolvidas, sendo também um estimulador da pesquisa nessa área específica. Além disso, os dados gerados nesse tipo de observação de campo podem ser integrados em um trabalho de conclusão de curso (TCC), potencializando a construção de uma consciência crítica da futura profissão de geólogo e mais direcionada para a sua função social.

\section{Referências bibliográficas}

ABGE. Associação Brasileira de Geologia de Engenharia e Ambiental. 2010. Definição de Geologia de Engenharia. São Paulo: ABGE. URL: http://www. abge.com.br/html $/$ modules. php?name $=$ Content $\& \mathrm{pa}=$ showpage\&pid=10. Acesso: 6.08.2010.

AEG. Association of Environmental \& Engineering Geologists. 2010. Engineering Geology. Denver: AEG. URL: http://www.aegweb.org/i4a/pages/ index.cfm? pageid=3862. Acesso: 6.08 .2010 .

Carneiro C.D.R., Toledo M.C.M. de; Almeida F.F.M. de. 2004. Dez motivos para a inclusão de temas de Geologia na Educação Básica. Rev. Bras. Geoc. 34(4):553-560.

Drummond C.N., Markin J.M. 2008. An analysis of the Bachelor of Science in Geology degree as offered in the United States. J. Geosc. Educ., 56(2):113-119.

Frodeman R. 2000. Earth matters: the Earth sciences, philosophy, and the claims of community. Upper Saddle River (NJ, EUA): Prentice Hall. 208p.

Lutz T., Srogi LA. 2010. A values framework for students to develop thoughtful attitudes about citizenship and stewardship. J. Geosc. Educ., 58(1):14-20. 


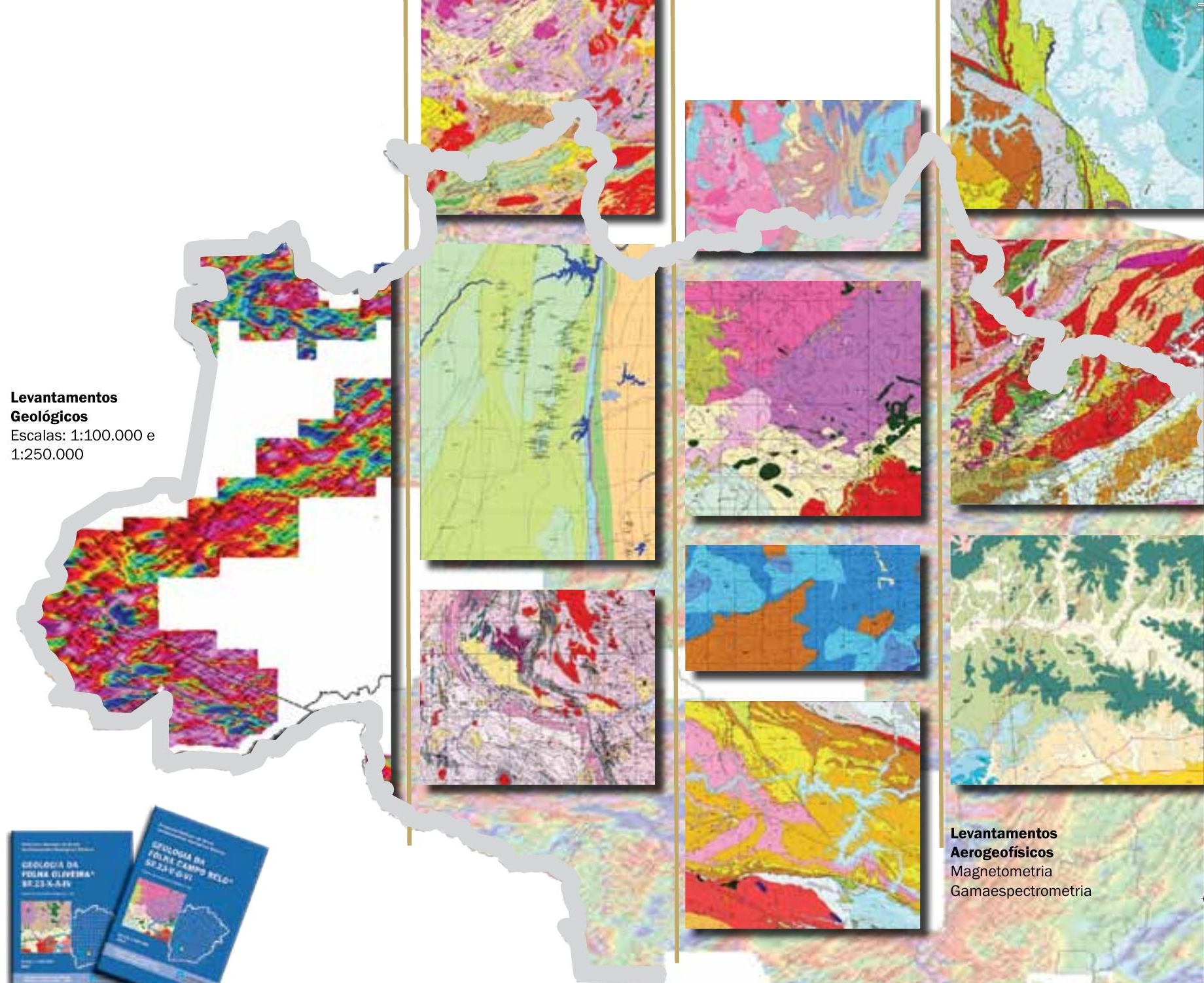

PROGRAMA GEOLOGIA DO BRASIL

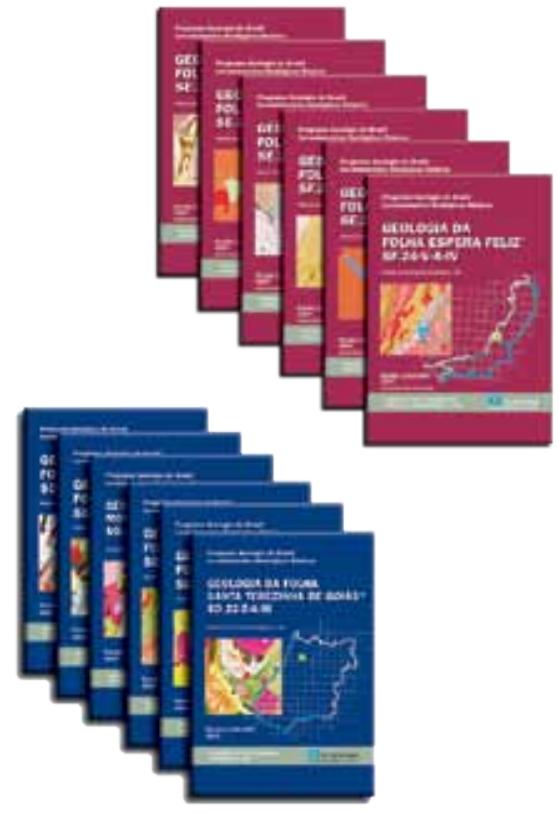

\section{RETOMADA DOS LEVANTAMENTOS GEOLÓGICOS E AEROGEOFÍSICOS BÁSICOS}

Novo ciclo de geração da informação geológica básica, revelando a força e o potencial do subsolo brasileiro.

Serviço Geológico do Brasil - CPRM (SEDE)

SGAN - Quadra 603 - Conjunto J - Parte A - $1^{\circ}$ andar

Brasília - DF - CEP: 70830-030

Tel.: 6133269500 / 6133224305 - Fax: 6132253985

Serviço de Atendimento ao Usuário - SEUS

Av. Pasteur, 404 - Urca - Rio de Janeiro - RJ - CEP: 22290-040

Tel: 21 2295-5997 - Fax: 21 2295-5897 - seus@cprm.gov.br

Ouvidoria

Tel: 21 2295-4697 - Fax: 21 2295-0495 - ouvidoria@cprm.gov.br

www.cprm.gov.br

Secretaria de

Geologia, Mineração e Transformação Mineral
Ministério de

Minas e Energia

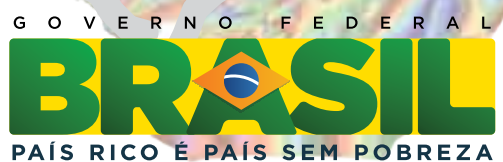

